\title{
Discussion on the Management of Electric Power Customer Complaints
}

\author{
Yanjun Pang ${ }^{1}$, Huiyan $\mathrm{Cao}^{1}$, Xiaoshu Zhang ${ }^{1}$, Xinhua Zhao ${ }^{1}$, Mei Xu ${ }^{1}$, \\ Wei $\mathrm{Ma}^{2}$, Yuhui Zhang ${ }^{2}$, Qinghao Wang ${ }^{1}$, Bo Zhu ${ }^{1}$ \\ ${ }^{1}$ Fushun Power Supply Company, Liaoning Electric Power Company Limited, State Grid, China \\ ${ }^{2}$ Liaoyang Power Supply Company, Liaoning Electric Power Company Limited, State Grid, China
}

Keywords: Service, Power Supply, Complaint, Management

\begin{abstract}
Quality service is the lifeblood of a power supply enterprise. It is a necessary requirement that improving the ability and level of quality service of power supply to meet the needs of economic and social electricity and establish socialistic harmonious society. It is an important content to expand electricity market and enhance the core competence of the corporation as well. Forewarning and occurrence management of the complaint to power supply is the process of gap management of service quality of enterprises inner,and so does the management of electricity customer satisfaction.
\end{abstract}

\section{Introduction}

In order to reduce the complaints. "Power supply regulation", "power supply service regulation" and so on have been introduced sequentially. The Power supply has been brought into standardized management category. And it will be requested by the government and all social circles higher and higher. Varieties of principal part of management ,especially the development of the private enterprises and the growth of awareness of the citizens' rights require the power supply to be more standardized rigorous high-quality and convenient. An important indicator that the high-quality enterprise service is good or bad is the rate of the customer complaints .State Grid Fushun Power Supply Company established a complete working mechanism which can reduce the complaint report management. The level of the moral culture construction and high-quality service has remarkably enhanced, economic benefits, management benefits and social benefits has increased.

By December 2015,Fushun Power Supply Company has happened a total of 143 complaints in all the complaints of Liaoning power supply this year, the complaint rate is $138 \%$,which was ranked seventh of 14 power supply companies in Liaoning. As shown in Fig. 1.

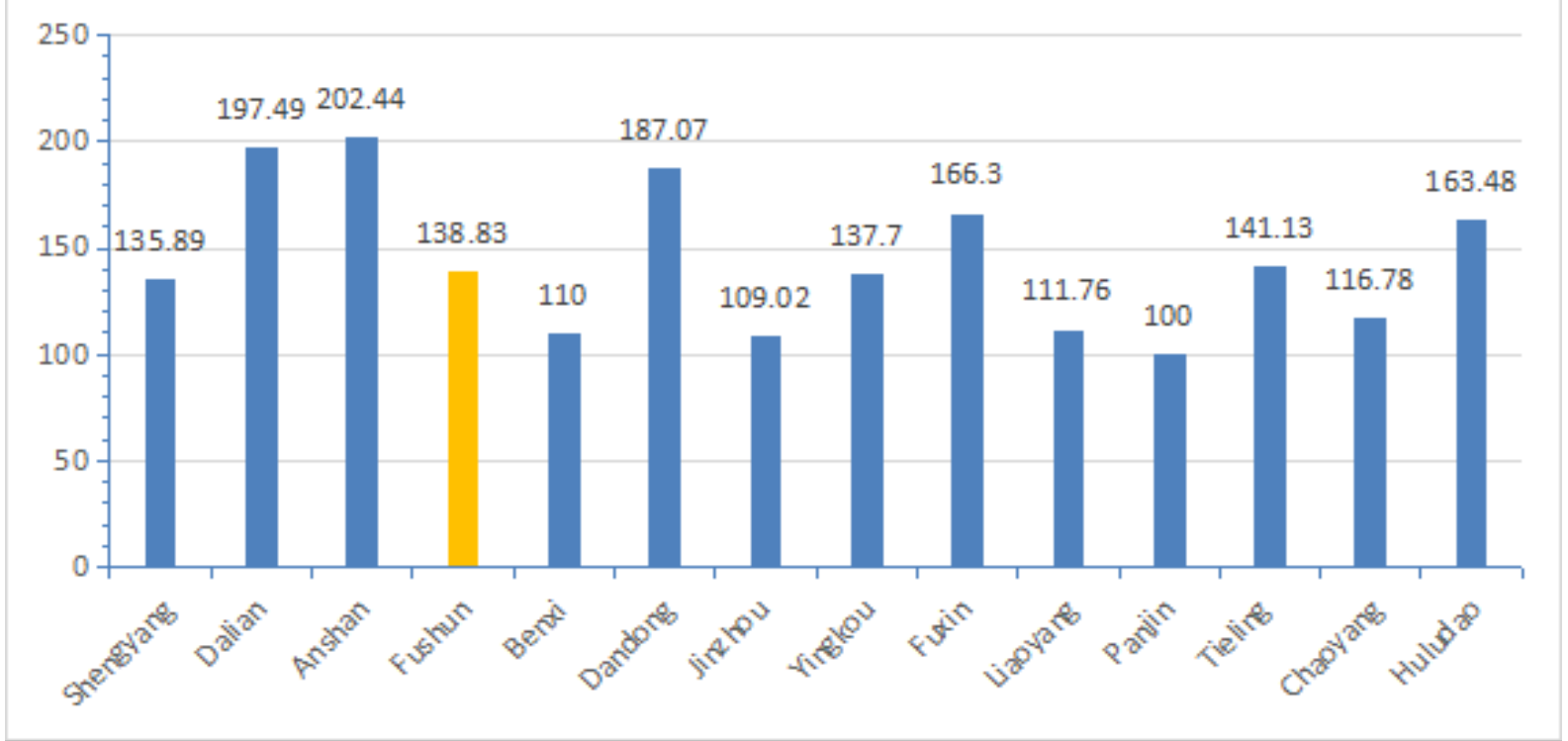

Fig. 1 The histogram of complaints of 14 power supply companies

The picture shows that the complaint rate of Fushun Power Supply Company is higher, on the premise of legal and rule, it is the desire of all staff to satisfy costumers' needs on high-quality 
service to make sure that the production and operation will be balanced and harmonious and reduce the complaint rate to improve the comprehensive satisfaction of customers.

\section{The Cause of the Customer Complaints}

People's expectations of the power supply service quality gets higher and higher everyday. As said: "A few words may induce the human smile, a few words may be mad the human to jump" .It always happens to power supply workers:

"Why did our electricity go off?"

"Why is there no outage notice today and yesterday? What has been happened?"

"Electrical is transmitted by the electric power supply company, I do not care about the line indoors or outdoors, you must solve the problem."

"Why is there no notices about my power going off?"

"The voltage of my home is not enough, that caused the lights flashing, why did it appear again after fixed last time."

"I have payed my bills after the power going off yesterday, why is there still no power now?What is happening?"

"Why are the emergency workers so slow to make me waiting so long, why do not send more people here?"

These are the problems faced by electric power supply workers, which will make more complaints if handled improperly, and influence the electric power supply service quality, even cause the great social impact.

Many power supply employees lacked the system capability to solve the complaints management, including service commitment, customer expectation, the gap of service quality and communication ability. The key of the core is lack of the capability of communication and Complaint handling for front-line staff. It is important to have the ability to solve the potential complaint specially for the junior managers and front-line staffs.

There are two aspects to complaint handling management:

First, how to avoid and reduce the probability of occurrence before the complaint taking place named the risk management of complaint.

Second, how to solve the complaint effectively first time after it happening named the management of customer complaints handling.

Risk management is better than the occurrence management in the relationship between them, the management of electric power customer satisfaction is the management process of the gap of enterprise service quality at the same time.

\section{Risk Management of Complaints}

The idea of risk management of power supply service should be discussed the applications from customer satisfaction, active service, sincere moment and services in accordance with the law. Resolving conflicts in time can eliminate the customer complaints in the bud.

\section{To know how to satisfy the customers.}

Customer service is not equal to customer satisfaction, that means "satisfaction" is not an absolute concept but a relative concept. Enterprises should be not made behind closed doors to focus on the subjective judgment of service attitude, product quality and the price, and examine the extent to which the products / services provided match customer expectations, requirements, and so on. So the power supply employees are asked to focus on the company system to focus on customer experience.

The active service of the power supply workers.

Initiative is a kind of working attitude, which means to find and satisfy the needs of customers actively. 


\section{The sincere moment of the power supply employee service.}

How to create a positive and sincere moment on power supply service should establish a system of the primary service, which can solve all the problems once in a power supply service site. The essence of it is the service system.

\section{Service according to law.}

Service according to law is the foundation and guarantee of the power supply quality service, following blindly expends the service scope virtually, even take over the customer's asset. Accepting the customer's requirement without preconditions increases the workload.

\section{Customer Complaints Management}

\section{A complaint is a gift.}

Customer complaints is not terrible, what terrible is that we can not treat the customer complaints well and stop up criticisms, this kind of service attitude is firmly rejected by us including stopping customers to complain, covering up customer complaints, thinking of customer complaints as find fault or be unreasonable. We should transfer the customer complaints as the precious gift given by customers, as the valuable source of the information for improving our work. Complaint is the lifeline of our growth and increase, the trust on us, a kind of resources and the test of our communication ability. Improving the cognition of the power supply employee can be prepared for customer complaints to make them look into the cause of customer complaints and the psychological states, it also can help the staff to establish the method and attitude when the customer complains.

The psychology and expectation of customer complaints.

Reason of the enterprise: 1 . The product quality defects; 2. Service quality; 3. Propaganda misleads; 4. Poor corporate governance.

Reason of the consumer: 1 . The relationship between the economic bearing capacity and the complaint of customer; 2. The relationship between the degree of ample leisure time and the complaint of customer; 3 . The relationship between personality traits and the complaint of customer; 4. The customer self-protection awareness enhanced .

Reason of the government supervision and social: 1 . The reason of government regulation; 2 . The legal system is unsound; 3. Social credit lacks.

\section{The seven steps of customer complaints and complaint handling.}

The first step: Accept and pacify, most of the customers are not friendly when they are complaining, some of them even swear with anger.no matter how bad the customer's attitude is, service staff should be enthusiasm ,thoughtful and polite to relieve anger and reduce the opposite attitude on both sides.

The second step: Collect the customer information, read meters from the power supply marketing information system and the charge for staff must know the customer information.

The third step: Master the customer type, analyze the customer complaints on which hand belonged to by the customer's dictation timely. Analyze the requirement of customer complaints from the customer's dictate, analyze the customer's requirement rationality at the same time and be necessary to communicate with the relevant department or ask the upper for instructions before the complaint solved if the specific problem belongs to them.

The fourth step: Communication skills, listen and face to the customer complaints with enthusiasm, the first of all is to listen carefully with the humble attitude as a reception personnel, and make a detailed record in "the registration form of customer complaints".

The fifth step: Understand customer's motivation and needs, customer's emotions will tend to rational usually after talking, there is a responsibility for us to get the necessary information through asking in order to understand the reason why made the customer unhappy and the customer's expectation this moment.

The sixth step: Solve the problem. In fact, we have transition to solve the problem naturally when you make the customer stay clam. 
The seventh step: Tracking service. Make a phone call to the customer to ensure the customer to satisfy our service and eliminate there unhappiness completely after the problem solved.

\section{Principle of Management}

The unity of the acceptance and feedback.

(1)Must be the first inquiry responsibility, reply by who accepted ("who"does not refer to the specific acceptance here)

(2)All of the service staff should be sincerity when handle the customer complaints, use business support system and check the related information.

(3)Give the customer a satisfactory answer when the problem can be coordinated and solved immediately. Explain to the customer and record in detail if the complaint can not be dealt with immediately. Fill in the electric order to submit to the relevant department or 95598 the customer service center.

\section{Emotional stability principle.}

(1)Control your emotion and stay calm and peaceful.

(2)Understand customer's mood, communicate, appease the customer's emotion and then deal with complaints.

\section{Actively cooperate with the principle.}

Although the primary responsibility was implemented, cooperate actively to help in the process of complaint handling.

\section{Neutral Principle}

Judge rationally by the customer complaints, do not contain personal emotion or likes and dislikes.

\section{Treatment specification.}

\section{a) Accept}

(1)Do not interrupt the customers when they are giving reasons of complaints. Let the customers out In order to avoid influence customers' mood

(2)Listen carefully, make the accurate memory, to be honest and do not make the customers repeat is in order to avoid the upgrade of the customer dissatisfaction.

(3)Response to customers timely to suggest the attention to the matter.

(4)Pay attention to ask the whole process of the event, speed should not be too fast, make a detailed complaint record.

\section{b) Clarify}

(1)Analyze the influence of the whole event on the customers rapidly according to their expressions.

(2)The problem can not be passed to the other department immediately when it is not known what the customer complains.

(3)Make the reasonable explanation and clarification from the perspective of customers. Pay attention to the tone of the interpretation, contempt, indifference or impatient can not be shown to the customers.

(4)In the process of explanation, do not argue with the customers or make excuses blindly, even try to pass the buck if there is the objection.

\section{c) Solve}

(1)Classify the problems according to the customers' complaints, there are three aspects which can be solved immediately, in short time and be solved at present which belongs to network technology.

(2)Explain the time and reason to need to solve the problem to the customers.

(3)Show the company's limited to the customers honestly if they do not accept the solution.

(4)According to the time limit stipulated of state grid corporation, send the complaint records which need the background processing to the related departments to deal with through system in 
time.

d) Take a follow up action and summarize

(1)Pay attention to follow up the progress of the complaint handling according to the requirements of process limited.

(2)Must return timely (by phone) in the process of waiting for the result.

(3)Inform the customer in time after the result coming out.

(4)Care about the customer satisfaction with the result of processing.

\section{Work Requirements and Process Procedure}

(1)Pay attention to the complainant's mode, explain patiently when disagreement, avoid to refuse directly.

(2)Determine the cause of the complaint, settle as soon as possible if there is a problem which must be solved immediately.

(3)Respond in time, the respond time should be told if can not reply. Report in a timely manner when beyond the discretion.

(4)Thanks or apologize to the customer after complaint handling, thank for their care.

\section{Conclusions}

It can continue to optimize the electric power supply service quality and improve customer satisfaction by risk management of the power supply complaints and processing timely after complaints. The characteristic of Commonality fundamental and service of the power supply company determines the work of marketing service to relate directly to the vital interest of the people and the development of the social. High-quality service is one of the unremitting theme of which the electric power supply company works for, of which the basis is improving the service consciousness, the core is the innovative service means and the guarantee is enhancing the service supervision.

\section{References}

[1] Zhang Haijuan. Exploration of Improving Service Quality and Reducing Power Customer Complaints. 2015 China Electric Power Education [J]. (29): 88-89

[2] Yan Chunrui. How to deal with Customer Complaints [J]. Eectric Power Science and Technology Information.2014 (26): 115-116

[3] Zhang Zhigang, Wang Pengfei. Study on the Management of Electric Power Customer Complaints. 2014 city construction [J]. (29): 82-83 